\title{
Changes in nerve function and endothelin level in patients with cerebral infarction after treatment with a combination of urinary kallidinogenase and edaravone
}

\author{
An Yan ${ }^{1}$, Min Yang ${ }^{2}$, Libo Cui ${ }^{2}$, Ping Chen ${ }^{3 *}$ \\ ${ }^{1}$ Department of Neurology, Affiliated Hospital of Beihua University, Jilin, Jilin Province, ${ }^{2}$ Heilongjiang Armed Police Corps \\ Hospital, Harbin, Heilongjiang, ${ }^{3}$ Department of Emergency Medicine, Nanjing Pukou District Central Hospital, Nanjing, Jiangbei \\ Province, China
}

*For correspondence: Email: zhuijichenxyji@163.com

Sent for review: 6 January 2021

Revised accepted: 3 April 2021

\begin{abstract}
Purpose: To investigate changes in neurological function and endothelin (ET) levels in cerebral infarction patients treated with combination of urinary kallidinogenase and edaravone.

Methods: Two groups of acute cerebral infarction patients on admission in our hospital from May 2017 to July 2019 were enrolled in this study. The control group (44 patients) received edaravone, while the study group (44 patients) was given urinary kallidinogenase combined with edaravone. Hemorheological indices, NIHSS scores, cerebral edema area, and ET levels, as well as the clinical effects of the treatments were compared. Incidence of major cerebrovascular adverse events during the 26-month follow-up period after treatment was recorded.

Results: Compared with the control group, the study group exhibited increase in shear whole blood viscosity, high shear whole blood viscosity and fibrinogen levels after the treatment $(p<0.05)$; however, lower NIHSS score, ET level and brain edema area were observed in the study group $(p<0.05)$. Total treatment effectiveness in the study and control groups was 95.45 and $79.55 \%$, respectively $(p<0.05)$. Fewer adverse cerebrovascular events were observed in patients in the study group (11.36 vs $29.55 \%$, $p$ < 0.05). Kaplan-Meier survival curve analysis revealed a mean event-free period of 16.12 months for the study group and 12.41 months for the control group $\left(X^{2}=14.868, p<0.001\right)$.

Conclusion: Urinary kallidinogenase combined with edaravone treatment yields a favorable effect in optimizing the hemorheological indices of cerebral infarction patients, reducing the degree of neurological deficits, and elevating ET levels.
\end{abstract}

Keywords: Cerebral infarction, Urinary kallidinogenase, Edaravone, Nerve function, Endothelin

This is an Open Access article that uses a fund-ing model which does not charge readers or their institutions for access and distributed under the terms of the Creative Commons Attribution License (http://creativecommons.org/licenses/by/4.0) and the Budapest Open Access Initiative (http://www.budapestopenaccessinitiative.org/read), which permit unrestricted use, distribution, and reproduction in any medium, provided the original work is properly credited.

Tropical Journal of Pharmaceutical Research is indexed by Science Citation Index (SciSearch), Scopus, International Pharmaceutical Abstract, Chemical Abstracts, Embase, Index Copernicus, EBSCO, African Index Medicus, JournalSeek, Journal Citation Reports/Science Edition, Directory of Open Access Journals (DOAJ), African Journal Online, Bioline International, Open-J-Gate and Pharmacy Abstracts

\section{INTRODUCTION}

Cerebral infarction, also known clinically as ischemic stroke, is a disorder in cerebral blood circulation. It refers to necrosis due to ischemia and hypoxia caused by sudden interruption of cerebral blood supply [1]. The disease is common in the middle-aged and elderly populations, associated with low cure rate, high degree of morbidity, disability and mortality, 
thereby constituting a serious threat to the lives and health of patients. Consequently, a shared desire for effective measures in treating cerebral infarction has been witnessed in clinical academia. Studies have shown that the inflammatory reaction induced by cerebral infarction leads to metabolic disorders and imbalance in the internal environment which predispose patients to neurological deficits, the severity of which is closely related to prognosis of patients [2,3].

At present, the clinical treatment for cerebral infarction involves prevention of infection, maintenance of anti-platelet aggregation, adequate brain nerve nutrition and blood lipid regulation. Edaravone is a preferred medicine due to its merits in removing oxygen free radicals and relieving cerebral edema [4]. However, application of a sole drug fails to succeed in stabilizing the patients. Thus, edaravone is administrated along with other drugs in clinical use. A study has indicated that the use of urinary kallidinogenase along with edaravone substantially enhances cerebral microcirculation, diminishes damage to patients' nerve function and promotes endothelin levels, resulting in a higher degree of safety [5]. This study was carried out to investigate the effect of treatment using combination of urinary kallidinogenase and edaravone on changes in nerve function and endothelin levels in patients with acute cerebral infarction.

\section{METHODS}

\section{Patients}

A total of 88 patients with acute cerebral infarction who were treated in Affiliated Hospital of Beihua University from July 2018 to July 2019 were enrolled in the study.

\section{Inclusion criteria}

The following category of patients were included: patients who met the diagnostic criteria for acute cerebral infarction in Diagnostic Essentials of Various Cerebrovascular Diseases formulated by the Chinese Neuroscience Association [6]; firstonset patients, patients with complete clinical data, and patients who willingly agreed to participate in the study.

\section{Exclusion criteria}

Patients with dysfunctions in liver, kidney, heart and in other important organs; those with cardiogenic embolism or other causes of cerebral infarction, patients with history of cerebral hemorrhage or cerebral infarction, and patients with mental illness or cognitive impairment, were excluded. This study received approval from the ethics committee of Affiliated Hospital of Beihua University.

The patients were divided into a study group and a control group, based on treatment schemes, with 44 patients/group. The control group consisted of 20 females and 24 males aged 45 82 years, with a mean age of $62.22 \pm 12.41$ years, and disease course of 5 to $70 \mathrm{~h}$ (mean disease course $=35.11 \pm 3.35 \mathrm{~h}$ ). The study group comprised 19 females and 25 males aged 45 - 81 years, with a mean age of $62.19 \pm 12.38$ years, and disease course of 6 -72 $\mathrm{h}$ (mean disease course $=36.05 \pm 3.39 \mathrm{~h}$ ). The general patient data were basically comparable in the two groups $(p>0.05)$.

\section{Treatment and procedures}

All patients underwent blood pressure and blood lipid regulation, and received basic treatments such as diuretic dehydration, oxygen inhalation, thrombolysis, nutritional support, and maintenance of water and electrolyte balance. The control group was given edaravone (Biomedical Engineering Center of Hebei Medical University; National Pharmaceutical Standards: H20090353; specifications: $30 \mathrm{mg} / 20 \mathrm{~mL}$ ) in the form of intravenous infusion containing $40 \mathrm{mg}$ in $250 \mathrm{~mL}$ of $0.9 \%$ sodium chloride, once a day. In addition to this treatment, patients in the study group received urinary kallidinogenase (Guangdong Tianpu Biochemical Pharmaceutical Co. Ltd.; National Pharmaceutical Standard: H20052065, specification: 0.15 PNA units/bottle) in the form intravenous infusion containing 0.15 PNA/100 $\mathrm{mL}$ of $0.9 \%$ sodium chloride, once a day. Both groups were treated continuously for two weeks.

\section{Evaluation of treatment indices}

\section{Hemorheological indices of the two groups before and after treatment}

The capillary viscometer method was applied for determination of blood rheology of the two groups (low shear whole blood viscosity, high shear whole blood viscosity and fibrinogen).

\section{National Institutes of Health Stroke Scale (NIHSS) score and edema area}

The NIHSS [7] was used for determination of the level of consciousness, facial paralysis, visual field, gaze, lower extremity movement, upper extremity movement, ataxia, speech, sensation, 
dysarthria, and neglect, based on a total score of 42 points. In the NIHSS, 0 point indicates normal neurological function, while a higher score indicates more severe neurological deficit.

\section{Levels of endothelin (ET) before and after treatment}

Early morning fasting elbow venous blood samples of all patients were collected before treatment, and after two weeks of treatment, for determination of human ET levels using sandwich double antibody enzyme-linked immunoassay (Shanghai Enzyme Biotechnology Co. Ltd).

\section{Clinical efficacy}

Clinical efficacy was classified as cured, effective and ineffective [8]. Following treatment, patients in whom symptoms such as language disorders, sensation at extremities, visual field deficits and other nerve functional impairments disappeared, and NIHSS score decreased by over $90 \%$, were regarded as cured. Treatment in patients in whom symptoms were significantly reduced after treatment, and the NIHSS score was decreased by 46 - 90\% was classified as markedly effective. If symptoms were relieved after treatment, and NIHSS score decreased by $18-45 \%$, the treatment outcome was regarded as effective. However, if the clinical symptoms were relieved after treatment, but NIHSS score decreased by less than $18 \%$, the treatment was regarded as ineffective. Total effectiveness was obtained via summation as shown in Eq 1.

$A(\%)=\{(B+C+D) / E\} 100 \ldots \ldots \ldots(1)$

where $A B, C, D$ and $E$ are total effectiveness; cured; markedly effective; effective; and total number of patients, respectively.

Total incidence of adverse cerebrovascular events and event-free survival curve analysis

Morbidity within 26 months after treatment was recorded through re-visit, re-hospitalization, telephone and follow-up, and the event-free survival analysis was carried out. Outcome events refer to the main adverse cerebrovascular events that occurred after the patient received treatment (cerebral atherosclerosis, intracranial cerebrovascular malformation and fatal and nonfatal ischemic stroke).

\section{Statistical analysis}

The SPSS version 19.0 software was used for statistical analysis of data. Qualitative data are presented as $\mathrm{n}(\%)$, and were compared with $\mathrm{X}^{2}$ test. Quantitative data that conformed with normal distribution are expressed as mean \pm standard deviation (SD), and were analyzed using $t$-test. Kaplan-Meier test was used for survival analysis, while Log-rank test was used to compare mean adverse cerebrovascular eventfree periods. The test level was $\alpha=0.05$. Values of $p<0.05$ indicated statistical significance of differences.

\section{RESULTS}

\section{Hemorheology indices}

Before treatment, no statistical differences of the low shear whole blood viscosity, high shear whole blood viscosity and fibrinogen values between the two groups were observed $(p>$ 0.05). However, after treatment, a decrease in low shear whole blood viscosity, high shear whole blood viscosity and fibrinogen levels in both groups was seen, in which the study group presented a greater degree of decline in comparison with the control group $(p<0.05)$. See Table 1.

\section{NIHSS score and cerebral edema area}

As shown in Table 2, similar results of the NIHSS score and cerebral edema area in the two groups before treatment were obvious $(p>0.05)$. However, after treatment, the study group garnered a smaller result of the NIHSS score and cerebral edema area than the control group ( $p<$ 0.05).

\section{ET levels}

Table 3 shows that the ET levels were comparable in the two groups before treatment $(p>0.05)$. However, post-treatment ET level was lower in the study group than in the control group $(p<0.05)$.

\section{Clinical effectiveness}

After treatment, the patients in the study group enjoyed a higher total treatment effectiveness than patients in the control group (95.45 vs 79.55 $\%)(p<0.05)$. See Table 4.

\section{Incidence of adverse cerebrovascular events and event-free survival}

The total incidence of adverse cerebrovascular events in the study group was $11.36 \%$, while that in the control group was $29.55 \%(p<0.05$; Table 5). Kaplan-Meier survival curve analysis showed that the mean adverse event-free period 
in the study and control groups were 16.12 and 12.41 months, respectively $\left(X^{2}=14.868, p<\right.$ $0.001)$, as shown in Figure 1.

\section{DISCUSSION}

Cerebral infarction is a relatively common critical cerebrovascular illness seen in clinical practice, with main clinical manifestations of tinnitus, dizziness and hemiplegia or short-term coma, and it had a high disability and mortality rates due to its complicated pathogenesis [9]. Its incidence accounts for 75 - $80 \%$ of cerebrovascular diseases, with about $60 \%$ of survivors subjected to different degrees of tinnitus, aphasia and paralysis and other dysfunctions which seriously affect their lives and health [10].

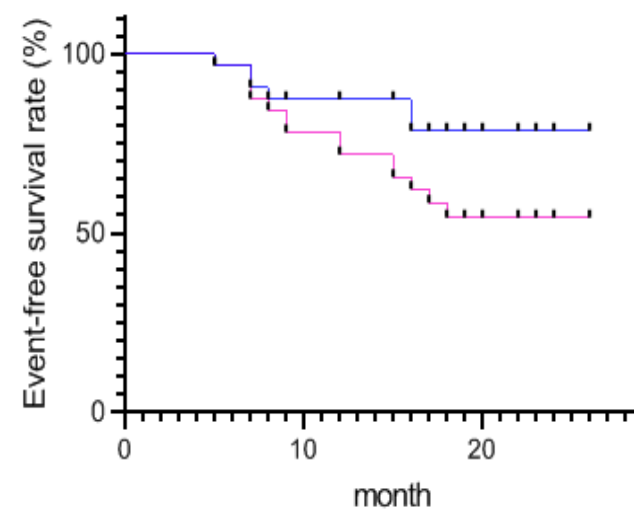

Figure 1: Kaplan-Meier survival curve analysis. Key: Dark curve $=$ study group; red curve $=$ control group

Table 1: Comparison of hemorheology indices between the two groups before and after treatment

\begin{tabular}{|c|c|c|c|c|c|c|}
\hline \multirow[t]{2}{*}{ Group } & \multicolumn{2}{|c|}{$\begin{array}{l}\text { Low shear whole blood } \\
\text { viscosity }(\mathrm{mPa} / \mathrm{s})\end{array}$} & \multicolumn{2}{|c|}{$\begin{array}{l}\text { High shear whole blood } \\
\text { viscosity }(\mathrm{mPa} / \mathrm{s})\end{array}$} & \multicolumn{2}{|c|}{ Fibrinogen(g/L) } \\
\hline & $\begin{array}{c}\text { Before } \\
\text { treatment }\end{array}$ & $\begin{array}{c}\text { After } \\
\text { treatment }\end{array}$ & $\begin{array}{c}\text { Before } \\
\text { treatment }\end{array}$ & $\begin{array}{c}\text { After } \\
\text { treatment }\end{array}$ & $\begin{array}{c}\text { Before } \\
\text { treatment }\end{array}$ & $\begin{array}{c}\text { After } \\
\text { treatment }\end{array}$ \\
\hline Study $(n=44)$ & $6.66 \pm 1.25$ & $3.06 \pm 0.77^{a}$ & $12.32 \pm 2.11$ & $7.60 \pm 1.11^{a}$ & $5.16 \pm 1.27$ & $3.08 \pm 0.45^{a}$ \\
\hline Control $(n=44)$ & $6.64 \pm 1.26$ & $5.97 \pm 0.90^{a}$ & $12.34 \pm 2.13$ & $11.06 \pm 1.25^{a}$ & $5.18 \pm 1.29$ & $4.76 \pm 0.64^{a}$ \\
\hline$T$ & 0.074 & 16.300 & 0.044 & 13.730 & 0.073 & 14.24 \\
\hline$P$-value & 0.940 & $<0.001$ & 0.964 & $<0.001$ & 0.942 & $<0.001$ \\
\hline
\end{tabular}

Table 2: Comparison of the NIHSS score and cerebral edema area between the two groups before and after treatment

\begin{tabular}{lcccc}
\hline Group & \multicolumn{2}{c}{ NIHSS score(point) } & \multicolumn{2}{c}{ Cerebral edema area(cm $\left.{ }^{2}\right)$} \\
\cline { 2 - 5 } & Before treatment & After treatment & Before treatment & After treatment \\
\hline Study $(\mathrm{n}=44)$ & $25.93 \pm 4.26$ & $11.93 \pm 2.16^{\mathrm{b}}$ & $6.02 \pm 1.35$ & $1.83 \pm 0.40^{\mathrm{b}}$ \\
Control $(\mathrm{n}=44)$ & $25.90 \pm 4.29$ & $18.12 \pm 2.70^{\mathrm{b}}$ & $5.99 \pm 1.33$ & $3.22 \pm 0.77^{\mathrm{b}}$ \\
$T$ & 0.033 & 11.870 & 0.105 & 10.630 \\
$P$ & 0.974 & $<0.001$ & 0.917 & $<0.05$ \\
\hline $\mathrm{b} P<0.05$ & \multicolumn{4}{c}{}
\end{tabular}

Table 3: Comparison of ET levels between the two groups before and after treatment

\begin{tabular}{lcc}
\hline Group & \multicolumn{2}{c}{ ET level } \\
\cline { 2 - 3 } & Before treatment & After treatment \\
\hline Study $(\mathrm{n}=44)$ & $84.42 \pm 11.20$ & $61.28 \pm 9.40^{\mathrm{c}}$ \\
Control $(\mathrm{n}=44)$ & $84.39 \pm 11.23$ & $75.43 \pm 10.31^{\mathrm{c}}$ \\
$T$ & 0.013 & 6.727 \\
$P$-value & 0.991 & $<0.001$ \\
\hline${ }^{\mathrm{c}} P<0.05$ & &
\end{tabular}

Table 4: Comparison of clinical treatment effect between two groups

\begin{tabular}{lccccc}
\hline Group & Cured & $\begin{array}{l}\text { Markedly } \\
\text { effective }\end{array}$ & Effective & Ineffective & $\begin{array}{c}\text { Total } \\
\text { effectiveness }\end{array}$ \\
\hline Study $(n=44)$ & $15(34.09)$ & $12(27.27)$ & $16(36.36)$ & $2(4.55)$ & $42(95.45)$ \\
Control $(n=44)$ & $7(15.91)$ & $18(40.91)$ & $10(22.73)$ & $9(20.45)$ & $35(79.55)$ \\
$X^{2}$ & & & & & 5.264 \\
$P$-value & & & & & 0.022 \\
\hline
\end{tabular}


Table 5: Comparison of total incidence of adverse cerebrovascular events

\begin{tabular}{lccccc}
\hline Group & $\begin{array}{c}\text { Cerebral } \\
\text { atherosclerosis }\end{array}$ & $\begin{array}{c}\text { Intracranial } \\
\text { cerebrovascular } \\
\text { malformation }\end{array}$ & $\begin{array}{c}\text { Fatal } \\
\text { ischemic } \\
\text { stroke }\end{array}$ & $\begin{array}{c}\text { Non-fatal } \\
\text { ischemic } \\
\text { stroke }\end{array}$ & $\begin{array}{c}\text { Total } \\
\text { incidence }\end{array}$ \\
\hline Study $(n=44)$ & 2 & 0 & 1 & 2 & $5(11.36)$ \\
Control $(n=44)$ & 4 & 2 & 3 & 4 & $13(29.55)$ \\
$X^{2}$ & & & & & 5.437 \\
$P$-value & & & & 0.020 \\
\hline
\end{tabular}

The development of cerebral infarction is firstly manifested as blockage of blood circulation, resulting in cerebral organ failure due to ischemia and hypoxia, and even necrosis of cerebral tissue and damage to nerve cells [11]. Therefore, the top priority in the treatment of cerebral infarction centers on promotion of blood circulation and recovery of damaged nerve function in the infarct area. These steps suppress ischemic cerebral injury, restore blood perfusion of tissues, reduce ischemia-reperfusion injury, and protect ischemia penumbra. Several studies have demonstrated that ET plays a vital role in the occurrence of ischemic cerebrovascular disease.

Monitoring of plasma ET is conducive to the assessment of changes in the disease state and prognosis, and serve as a guide in the prevention and treatment of cerebral infarction to a certain degree $[12,13]$. At present, clinical treatment measures for cerebral infarction involve interventional therapy, intravenous thrombolysis and drug therapy. Remarkable effects which have been proven in interventional and intravenous thrombolytic therapies notwithstanding, are undermined by various complications and a poor prognosis. Therefore, targeted treatment measures should be adopted in clinical treatment in accordance with the actual condition of the patient.

It was found in a study that the use of kininogenase drugs effectively promoted the secondary growth of infarct blood vessels, mitigated ischemic conditions, and restored nerve function [14]. The main component of urinary kallidinogenase is human fibrinogenase. The kinin moiety dilates blood vessels, promotes blood circulation in the brain, induces growth of blood vessels in cerebral ischemia sites, and improves microcirculation in patients' brain tissues [15]. In addition, urinary kallidinogenase ameliorates the repair of patients' neurological function by inhibiting neuronal apoptotic cells, and substantially abates the inflammation in patients. Moreover, the drug is appreciated by a low incidence of adverse reactions and a high safety [16]. Edaravone, one of the frequently used free radical scavengers in clinics, effectively inhibits the activity of xanthine oxidase and hypoxanthine oxidase, prevents the formation of inflammatory mediators, and reduces the concentration of hydroxyl radicals [17]. The combination of these two drugs may exert a synergistic effect in clinics, thereby enhancing the therapeutic effects which are of critical significance for reducing patients' adverse symptoms and improving prognosis [18]. This study showed that after treatment, the low shear whole blood viscosity, high shear whole blood viscosity, and fibrinogen of the two groups decreased, with decreases in the study group being more remarkable, indicating that the combination of treatment produced a satisfactory effect on cerebral infarction. The efficient mitigation on the patients' blood rheology indicators, in all probability is on consequence of the inhibitory effect of urinary kallidinogenase on platelet aggregation and its enhancing effect on red blood cell deformation. After treatment, the NIHSS score and brain edema area of the study group were smaller than those of the control group, indicating that urinary kallidinogenase and edaravone yielded a significant clinical efficacy, repaired nerve function, and reduced the area of cerebral edema. It is essential to treat cerebral infarction timely so as to restore cerebral perfusion: the degree of capillary hyperplasia is closely related to the status of blood flow around the ischemic site [19].

Angiogenesis effectively optimizes the survival and the prognosis of cerebral infarction patients. The number of new blood vessels is also closely related to the degree of nerve regeneration. New blood vessels relieve the symptoms of tissue hypoxia and ischemia and promote neuronal repair [20]. The present study revealed that the ET level in the study group was lower after treatment, suggesting that the combination of urinary kallidinogenase and edaravone evidently bring down ET level. Endothelin (ET) is a strong vasoconstrictor peptide which diminishes endothelial damage and inhibits the proliferation of vascular endothelial smooth muscle cells [21]. Urinary kallidinogenase activates $\beta 1$ receptors in the brain tissue of patients, and increases intracellular calcium ion contents, thereby reducing ET concentration, improving brain microcirculation, and driving down the extent of brain lesion. Thus, the combined use of urinary 
kallidinogenase and edaravone creates a synergy which improves vascular endothelin levels, reduces microthrombosis, andoptimizes cerebral blood flow.

This study recorded the occurrence of major cerebrovascular adverse events during the 2year follow-up after treatment. The results showed that the study had lower total incidence of adverse cerebrovascular events, and based on the Kaplan-Meier survival curve, the adverse cerebrovascular event-free period in patients in the study group was longer than that of control patients. These results suggest that treatment of cerebral infarction with combination of urinary kallidinogenase and edaravone is beneficial to patients' short-term prognosis and their quality of life.

\section{Limitations of the study}

The shortcomings in this study are as follows: being a hospital-based case-control study, the sample size collected was small, and the observation period for prognosis was short. Therefore, there is need for use of a larger sample size and longer observation period in subsequent studies.

\section{CONCLUSION}

The clinical efficacy of the combination of urinary kallidinogenase and edaravone for the treatment of cerebral infarction produces marked beneficial outcomes. It effectively improves blood rheology indices of patients, reduces the degree of neurological deficits, decreases the level of ET-1, and enhances the short-term prognosis of patients.

\section{DECLARATIONS}

\section{Conflict of interest}

No conflict of interest is associated with this work.

\section{Contribution of authors}

We declare that this work was done by the authors named in this article and all liabilities pertaining to claims relating to the content of this article will be borne by the authors.

\section{Open Access}

This is an Open Access article that uses a funding model which does not charge readers or their institutions for access and distributed under the terms of the Creative Commons Attribution License (http://creativecommons.org/licenses/by/ 4.0) and the Budapest Open Access Initiative (http://www.budapestopenaccessinitiative.org/rea d), which permit unrestricted use, distribution, and reproduction in any medium, provided the original work is properly credited.

\section{REFERENCES}

1. Shu YH. Clinical effect observation of edaravone combined with naoxintong capsule in treatment of acute cerebral infarction. Journal of Huaihai Medicine. 2014; 42(7): 694-695.

2. Song TJ, Chang Y, Chun MY. High dietary glycemic load is associated with poor functional outcome in patients with acute cerebral infarction. J Clin Neurol. 2018; 14(2): 165-173.

3. Tamer TM, ValachováK, Hassan MA. Chitosan/hyaluronan/edaravone membranes for antiinflammatory wound dressing: In vitro and in vivo evaluation studies. Materials Science \& Engineering $C$ Materials for Biological Applications. 2018; 90(7): 227228.

4. Muhl L, Kulin J, Dagonnier M. Mobilization after thrombolysis (rt PA) within 24 hours of acute stroke: what factors influence inclusion of patients in A Very Early Rehabilitation Trial (AVERT). BMC Neurol. 2014; 14 (1): 163.

5. Umemura T, Yamamoto J, Akiba D. Bilateral cerebral embolism as a characteristic feature of patients with Trousseau syndrome. J Clin Neurosci. 2017; 42: 155159.

6. Hahne K, Mnnig G, Samol A. Atrial fibrillation and silent stroke: links, risks, and challenges. Vasc Health Risk Manag. 2016; 12: 65-74.

7. Hart RG, Catanese L, Perera KS. Embolic stroke of undetermined source: a systematic review and clinical update. Stroke. 2017; 48(4): 867-872.

8. Chen B, Zhang F, Li QY. Protective effect of Ad-VEGFBone mesenchymal stem cells on cerebral infarction. Turk Neurosurg. 2016; 26 (1): 8-15.

9. Zhao JH, Xu YM, Xing HX. Associations between matrix metalloproteinase gene polymorphisms and the development of cerebral infarction. Genet Mol Res. 2016; 14 (4) :19418-19424.

10. Liu J, Zhu Y, Wu Y. Association of carotid atherosclerosis and recurrent cerebral infarction in the Chinese population: a metaanalysis. Neuropsychiatr Dis Treat. 2017; 13: 527- 533.

11. Skoro-Sajer N, Gerges C, Gerges M. Usefulness of thrombosis and inflammation biomarkers in chronic thromboembolic pulmonary hypertension-sampling plasma and surgical specimens. J Heart Lung Transplant. 2018; 37(9): 1067-1074.

12. Piccardi B, Giralt D, Bustamante A. Blood markers of inflammation and endothelial dysfunction in 
cardioembolic stroke: systematic review and metaanalysis. Biomarkers. 2017; 22(3-4): 200-209.

13. Margulescu $A D$, Mont L. Persistent atrial fibrillation vs paroxysmal atrial fibrillation: differences in management. Expert Rev Cardiovasc Ther. 2017; 15(8): 601-618.

14. Poggesi A, Pasi M, Pescini F. Circulating biologic markers of endothelial dysfunction in cerebral small vessel disease: A review. J Cereb Blood Flow Metab. 2016; 36(1): 72-94.

15. Li C, Zhao GF, He QY. Study on the clinical efficacy of Human Urinary Kallikrein in the treatment of acute cerebral infarction according to TOAST classification. Pak J Pharm Sci. 2015, 28(4 Suppl):1505-1510.

16. Merchant FM, Delurgio DB. Catheter ablation of atrial fibrillation and risk of asymptomatic cerebral embolism. Pacing Clin Electrophysiol. 2014; 37(3): 389-397.

17. Li MM, Lin YY, Huang YH. Association of apolipoprotein $A 1, B$ with stenosis of intracranial and extracranial arteries in patients with cerebral infarction. Clin Lab. 2015; 61 (11): 1727-1735.

18. Song TJ, Chang Y, Chun MY. High dietary glycemic load is associated with poor functional outcome in patients with acute cerebral infarction. J Clin Neurol. 2018,14(2): 165-173.

19. Dehghan-Shasaltaneh M, Naghdi N, Choopani S. Determination of the best concentration of streptozotocin to create a diabetic brain using histological techniques. J Mol Neurosci, 2016, 59 (1): 24-35.

20. Neto ACL, Bittar R, Gattas GS. Pathophysiology and Diagnosis of Vertebrobasilar Insufficiency: A Review of the Literature. International Archives of Otorhinolaryngology. 2017; 21(3): 302-307.

21. Neto ACL, Bittar R, Gattas GS. Pathophysiology and Diagnosis of Vertebrobasilar Insufficiency: A Review of the Literature. International Archives of Otorhinolaryngology. 2017; 21(3): 302-307. 